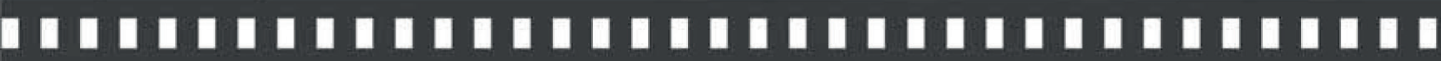

\section{A retórica da imagem na grande reportagem transmídia}

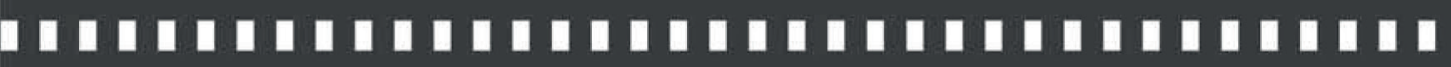

Mauro de Souza Ventura

Liliane de Lucena Ito

Artigo recebido em: 25/02/2016

Artigo aprovado em: 02/12/2016 


\title{
A retórica da imagem na grande reportagem transmídia
}

\section{The rhetoric of the image in the transmedia news report}

\author{
Mauro de Souza Ventura* e Liliane de Lucena Ito**
}

\begin{abstract}
Resumo: Este artigo parte do pressuposto de que, no jornalismo, as fotografias podem cumprir várias funções, entre elas, informar e também persuadir, aproximando-se daquelas produzidas para fins publicitários. Com base na metodologia proposta por Umberto Eco em A estrutura ausente, este texto analisa fotografias produzidas para uma reportagem digital. Os resultados indicam a existência de articulações semelhantes às observadas em peças publicitárias, contudo, com algumas diferenciações.
\end{abstract}

Palavras-chave: Fotografias ilustrativas. Jornalismo. Reportagem transmídia. TAB.

\begin{abstract}
This article assumes that, in journalism, pictures can fulfill several functions, including informing and persuading too, approaching to those produced for advertising purposes. Based on the methodology proposed by Umberto Eco in The absent structure, this text analyzes photographs produced for a digital report. The results indicate the existence of articulations similar to those seen in advertisement pieces, however, with some differences.
\end{abstract}

Keywords: Illustrative photos. Journalism. Transmedia story. $T A B$.

* É graduado em Comunicação Social - Jornalismo pela PUCRS (1986), possui mestrado em Jornalismo e Editoração pela ECA - USP (1995) e doutorado em Letras (Teoria Literária e Literatura Comparada) pela FFLCH - USP (2000). Realizou estágios de Pós-Doutoramento no Departamento de Teoria Literária do IEL - UNICAMP (2005-2006) e no Institut für Publizistik- und Kommunikationswissenschaft, da Universidade de Viena (2011). Atualmente, é Coordenador do Programa de Pós-Graduação em Comunicação (Mestrado) da UNESP/Bauru e Professor do Curso de Jornalismo da FAAC/UNESP/Bauru. É também editor da Revista Comunicação Midiátiática (PPGCOM-UNESP). ** Doutoranda em Comunicação pelo PPGCOM-UNESP. Bolsista Capes. 


\section{Introdução}

Não é possível imaginar, hoje, um mundo desprovido de imagens fotográficas. A invenção da fotografia foi essencial para a entrada da vida humana em uma era predominantemente visual da qual parece não ser mais permitido sair. Segundo Freund (1995), a relação entre a estrutura da sociedade e suas expressões artísticas é total, sendo que uma é capaz de influenciar a outra, numa relação de dependência mútua. Dessa forma, fotografias funcionam como documentos sociais de uma determinada época, sendo possível caracterizar valores em voga, marcados em seu espaço e tempo, numa produção fotográfica.

Dentro desse pressuposto - o de que a fotografia é um documento social - observam-se no fotojornalismo transformações longitudinais, ou seja, mutações ocorridas ao longo das décadas tanto em seus aspectos técnicos quanto em sua inserção nos veículos de comunicação. De seu surgimento na Alemanha em 1930, passando pela época de ouro (com Life, Paris Match, O Cruzeiro, Realidade) e por sua fase ideológica para, posteriormente, perder tal característica, o fotojornalismo tem acompanhado efetivamente o cenário social, político, cultural e econômico de cada momento histórico.

Alguns pensadores mais radicais defendem que o fotojornalismo morreu. Não haveria mais espaço para esse tipo de produção na imprensa hoje. Persichetti (2006) faz uma defesa menos extremista ao ponderar que houve, sim, uma certa "morte" do gênero, mas apenas se esta estiver relacionada ao fim do fotojornalismo engajado em detrimento de imagens estéticas, que espetacularizam e não informam. "Temos uma imprensa baseada no personalismo, na foto posada, deixamos de ter a ação. Embora a tecnologia nos permita fazer coisas impensáveis, é nossa cabeça que não pensa" (PERSICHETTI, 2006, p. 185).

Entretanto, se presenciamos um enxugamento de espaço do fotojornalismo na mídia impressa, deve-se levar em consideração 
que isso coincide com o enxugamento da própria mídia impressa (em consumo de exemplares e receita de publicidade), algo que vem ocorrendo pouco a pouco no mundo todo há décadas (RIGHETTI; CARVALHO, 2008), o que sinaliza para as empresas de mídia uma urgência por reinvenção e adaptação ao consumo jornalístico da forma como é feito no presente (ANDERSON; BELL; SHIRKY, 2013). No setor de revistas, especificamente, periódicos com anos de mercado desaparecem ou são vendidos por não representarem mais uma fonte de lucro como antes, como é o caso dos vários títulos da Editora Abril que foram descontinuados ou postos à venda desde 2013 (ARAGÃO; FABIO,2015), o que coincide, logicamente, com a demissão de jornalistas e outros profissionais que lidam com a mídia.

O cenário contemporâneo é de migração de uma cultura de difusão para uma cultura de convergência (JENKINS, 2008), que influencia a transformação do consumo de produtos midiáticos. Isso pode significar não somente a perda de leitores em segmentos determinados da mídia impressa, como também a possibilidade de expansão de modelos de negócio, além de ser um momento propício para que novos veículos, genuinamente criados na e para a internet, legitimem-se e inovem na forma de publicar uma ampla gama de gêneros informativos, inclusive o fotojornalismo.

Se o fotojornalismo anda esquecido devido a uma série de fatores, na qual a crise de vendas da matriz impressa é talvez a mais óbvia, a situação se transforma nos ambientes convergentes digitais. Casadei (2014) defende que, na atualidade, surgem espaços inéditos de autoria para o fotojornalista, bem como ocorre uma revalorização de seu trabalho ancorada em novas lógicas de produção autoral, uma vez que as narrativas podem circular de maneiras distintas das impostas no meio impresso, no sustento de projetos fotojornalísticos via métodos inovadores, como o crowdfunding, e na possibilidade de se fazer produções multimídia que, por conta de seu caráter híbrido, possibilitam novos efeitos de referencialidade. 
Assim, surgem plataformas até então inéditas de publicação para o fotojornalismo, com possibilidades inexploradas por conta da limitação dos meios não convergentes. $E$, juntamente a isso, podem ressurgir formatos que vinham minguando pouco a pouco nas chamadas mídias tradicionais. "A convergência midiática teve como uma de suas consequências a revitalização da grande reportagem fotojornalística, que não mais se confina ao material impresso" (CASADEI, 2014, p. 201). Materiais audiovisuais como slideshows e picture stories são alguns dos exemplos de novas configurações em que a fotografia se insere num momento de convergência de linguagens e mídias.

Dentro desse cenário, este artigo tem por objetivo apresentar reflexões sobre a utilização da fotografia em produtos jornalísticos digitais, mais precisamente na reportagem digital transmídia, formato marcado por elementos como a interatividade e a multimidialidade. Com base em revisão bibliográfica, busca-se problematizar o uso da fotografia em duas grandes vertentes comuns a esse tipo de publicação: a foto referencial e a foto ilustrativa. A partir da metodologia proposta por Umberto Eco (2007), em $A$ estrutura ausente, são analisadas duas imagens de edições distintas do $\mathrm{TAB}$, série de reportagens transmídia veiculada pelo UOL semanalmente.

Trabalha-se com duas hipóteses centrais: a de que a metodologia proposta por Eco inicialmente para análise de peças publicitárias pode ser ampliada para determinadas imagens presentes no jornalismo (especificamente as do segundo grupo acima citado) e a de que tais fotografias exercem função persuasiva semelhante ao que se encontra em discursos publicitários. Entre os resultados, nota-se uma redundância retórica da fotografia, que claramente reforça a angulação jornalística dada ao texto, além da confirmação sobre a viabilidade de utilização da metodologia de Eco, desde que se atente a certas diferenciações importantes entre a visão que o autor confere ao código publicitário e a existente no código jornalístico, uma vez que pode se inverter a ancoragem entre 
texto e imagem nesses dois tipos distintos de mensagem.

\section{Novos espaços para o fotojornalismo}

No gênero denominado como grande reportagem multimídia por Longhi (2014), as imagens são fundamentais, tendo a fotografia como protagonista em muitos exemplares publicados no Brasil e no mundo. A autora traça uma linha do tempo do jornalismo digital, começando nas primeiras tentativas dos grandes veículos em criar conteúdo multimídia, dezesseis anos atrás, para, em 2012, advir uma fase nova, possibilitada por avanços técnicos (da extensão da banda larga ao surgimento do HTML5), capaz de inaugurar um gênero noticioso (o da grande reportagem multimídia) cujas características são a imersão no conteúdo de forma longa (long form), apurado, contextualizado e aprofundado, em que recursos multimídias, hipertextuais e interativos são essenciais para a construção de significado. A grande reportagem multimídia representa, para o jornalismo digital, um grande ganho de qualidade editorial em relação aos formatos anteriores, como a webnotícia, no geral fragmentados ou com pouca profundidade temática.

Canavilhas (2014) e Renó (2014) oferecem distinções conceituais que podem delimitar de maneira ainda mais adequada a reportagem digital. Eles acrescentam a noção de transmidialidade, quando as narrativas extrapolam linguagens e plataformas em conteúdos produzidos com a intenção de expandir o texto-base, sem, entretanto, que estes materiais sejam obrigatórios para o entendimento do enredo ou da narrativa. "Transmídia é uma linguagem contemporânea e social construída por vários conteúdos através de diferentes mídias com significados independentes, mas coletivamente oferecendo um novo significado" (RENÓ, 2014, p. $5)$.

O conceito de transmídia poderia, então, ser aplicado à reportagem digital quando não é definida somente pela 
característica multimídia, já que há a possibilidade de o próprio material multimídia que compõe a narrativa estar disponível em outros ambientes (como uma rede social ou plataforma de vídeos), sem a perda de significado do fragmento em questão ${ }^{1}$ - uma vez que se trata de um conteúdo com início, meio e fim que, apesar de contribuir em profundidade e ilustração para a reportagem, pode também ser consumido e compreendido em contexto distinto do de sua origem. Entretanto, ao contribuir para a formação de um universo sobre a narrativa, a transmidialidade impulsiona o consumo do material como um todo: "a compreensão obtida por meio de diversas mídias sustenta uma profundidade de experiência que motiva mais consumo" (JENKINS, 2008, p. 135).

No webjornalismo, o formato mais potencialmente transmidiático, por apresentar conteúdos multimídia e interativos, é o da reportagem:

Os gêneros jornalísticos verdadeiramente adaptados à narrativa transmídia são os gêneros nativos do jornalismo na Web (newsgames e infográficos multimídia interativos), mas sobretudo a grande reportagem, um gênero transversal a todas as mídias (CANAVILHAS, 2014, p. 64).

O autor acrescenta que a transmidialidade apresenta características-chave, que são: interatividade, hipertextualidade, multimidialidade integrada (em que o conteúdo visual ou sonoro

1 Um exemplo de reportagem transmídia é a edição número 4 da série $\mathrm{TAB}$, do portal UOL, Todo mundo mente, que traz vários vídeos (elementos multimídia). Alguns desses vídeos foram compartilhados no Facebook. Eles contêm ilusões de ótica, temática tangente ao tema do texto, que é "Mentira". Na narrativa, os vídeos funcionam como ilustrações de como nosso olho "produz" mentiras em nosso cérebro; já na rede social, os vídeos são apresentados como curiosidades avulsas. Entretanto, quem assiste aos vídeos na rede social pode se sentir impelido a consumir toda a reportagem - e então, clicar no link que direciona à sua leitura. 
é usado de maneira a confirmar, destacar ou ilustrar algo) e contextualização (que se refere à necessidade de adaptação do conteúdo aos hábitos de leitura do usuário em diferentes contextos, principalmente móveis).

No Brasil, um dos veículos que mais têm apostado em reportagens do tipo é a Folha de S.Paulo, cujo marco inicial foi a cobertura sobre Belo Monte, publicada no próprio site em 2013. A reportagem, com cinco capítulos, contém uma gama considerável de recursos multimídia com potencial transmidiático, como infográficos animados, galeria de imagens, vídeos e um videojogo. O material demandou quase dez meses para ser construído e envolveu, de forma direta ou indireta, 15 jornalistas.

Em outubro de 2014, o portal UOL, quinto maior em audiência web no Brasil (e pertencente ao Grupo Folha, que edita a Folha de S.Paulo), passou a publicar a série de reportagens TAB. Com veiculação semanal, TAB traz textos que abordam questões contemporâneas, muitas vezes controversas e provocativas, em caráter imersivo e interpretativo. Todas as edições, sem exceção, fazem uso de recursos multimídia, além de interatividade e hipertextualidade.

As reportagens do TAB são veiculadas às segundas, com grande destaque na home do portal. Segunda-feira é o dia de maior acesso ao site $^{2}$, o que consequentemente garante uma visibilidade maior desse conteúdo pelos usuários. O produto segue um modelo de negócio diferente do restante do conteúdo jornalístico produzido pelo UOL, uma vez que é abertamente patrocinado por outras empresas e marcas. A publicidade, por sua vez, é fixa, sendo que apenas uma marca patrocina cada edição, aparecendo em momentos específicos e estratégicos ${ }^{3}$, sem contribuição ou inserção

2 Informação consta na reportagem $U O L$ lança o TAB, novo projeto editorial interativo, disponível em $<\mathrm{http}$ :/noticias.uol.com.br/ultimas-noticias/ redacao/2014/10/13/uol-lanca-o-tab-novo-projeto-editorial-interativo.htm $>$.

3 A publicidade aparece logo no início da reportagem, quando o usuário precisa obrigatoriamente assistir a um vídeo de 5 segundos para acessar o conteúdo, e um pouco antes do final da mesma, no momento em que outro vídeo 
no conteúdo jornalístico em si.

Em relação ao visual, o layout do TAB é planejado conforme a temática da pauta, como acontece nos suplementos especiais de jornais ou em revistas segmentadas. Entretanto, segue um padrão interno de apresentação e faz uso do efeito parallax scrolling. Ao rolar a tela para baixo, conforme a leitura avança (uma vez que a narrativa do TAB é vertical), certos elementos ganham movimento, muitas vezes de forma discreta, outras vezes de forma mais visível, fazendo com que a leitura do texto longo seja menos cansativa e mais agradável. O parallax scrolling simula o efeito $3 \mathrm{D}$ e, devido a isso, é utilizado na indústria de games há décadas.

Os elementos inovadores de apresentação de conteúdo, como se pode concluir, requerem novas habilidades dos jornalistas, além da inclusão de especialistas de outras áreas, como programadores, na redação. "Atualmente, quem desejar explorar ao máximo o potencial comunicativo da internet necessita contar com excelentes dotes de escritor e com grandes aptidões para a narrativa gráfica e audiovisual" (SALAVERRÍA, 2014, p. 33). Renó (2014), afirma que vivemos o momento das narrativas transmidiáticas, que possuem um espaço privilegiado hoje. E, para isso, o jornalista precisa ser interdisciplinar e multiplataforma.

\section{O casamento entre fotografia e multimídia}

Apesar de aparentemente remeter à internet, a origem de textos multimídia é muito anterior às tecnologias em rede. Salaverría (2014) lembra que o jornal impresso, com a evolução das técnicas de reprodutibilidade e a inclusão das primeiras gravuras, no final do século XIX, inaugura a mídia multimídia, uma vez que duas linguagens estavam ali inseridas (a visual e a textual).

Um conteúdo pode expressar-se, efetivamente, através de

surge, mas sem a obrigatoriedade de ser assistido. 
um único tipo de linguagem - texto, som, fotografia... ou através de vários tipos de linguagem em simultâneo. Quando o conteúdo se expressa através de um único tipo de linguagem, encontramo-nos perante um conteúdo monomédia. Seguindo o mesmo critério, se combinarmos dois tipos de linguagem estamos perante um conteúdo bimédia; se forem três, trimédia, e assim sucessivamente. Segundo este critério, todos os conteúdos que contam com pelo menos dois tipos de linguagem associados entre si são, por natureza, multimédia. Dito de outro modo, qualquer mensagem que não seja monomédia é multimídia. (SALAVERRÍA, 2014, p. 30, destaque do autor)

Em relação aos conteúdos jornalísticos multimídia, Salaverría defende que este tipo de material deve buscar informar para os cinco sentidos, explorando assim todas as possibilidades multimidiáticas disponíveis - talvez no futuro, consiga-se expandilas para o olfato e paladar ${ }^{4}$. Segundo o autor, atualmente, os conteúdos multimídia podem ser constituídos por oito elementos diferentes: 1) texto; 2) fotografia; 3) gráficos; 4) iconografia e ilustrações estáticas; 5) vídeo; 6) animação digital; 7) discurso oral, música e efeitos sonoros; e 8) vibração. O papel da imagem numa narrativa multimídia é tão central que, diante dos elementos citados por Salaverría, percebe-se que cinco deles são imagéticos, podendo incorporar, nos quatro que não são fotografias propriamente ditas, imagens fotográficas.

Entretanto, analisando de maneira exploratória o que está disponível hoje como recurso multimídia em reportagens transmídia, é possível notar a presença da imagem fotográfica em duas grandes vertentes: 1) a que se aproxima do fotojornalismo, principalmente em galerias de imagem; e 2) aquela que se aproxima

$4 \quad$ O tato já está presente, mas sem ter suas potencialidades comunicativas bem exploradas. Certos dispositivos eletrônicos já podem, no entanto, vibrar conforme a ação do usuário. 
da publicidade, uma vez que se cerca de redundâncias retóricas para ilustrar e afirmar o que é dito no texto.

A primeira vertente é vista em pictures stories, fotorreportagens e especiais multimídia em que os fotografados são personagens reais e as imagens são capturadas durante uma cobertura fotográfica específica ${ }^{5}$. Tais imagens são dispostas em galerias de imagens (slideshows) acompanhadas ou não de áudio; podem servir como referência em $360^{\circ}$ a um local ao qual o texto se remete; e servir de base para infografias animadas que mostrem diferentes recortes cronológicos de um determinado processo; entre outras possibilidades. Nessas imagens, há uma intenção de que a fotografia seja, em essência, o mais próximo da realidade capturada, referencial. Essa vertente de imagens pode ser encaixada como "informativa" (MEDINA; LEANDRO, 1973) ou "spot-news" (SOUZA, 1997).

Entretanto, nas imagens do segundo grupo, em que a fotografia se aproxima da publicidade, a intenção é outra: convencer o leitor também por meio da narrativa visual, aproximando-se muitas vezes de recursos publicitários. Essas fotografias não se enquadram no fotojornalismo. São imagens produzidas para ilustrar um determinado tema e muito comuns em revistas segmentadas. São as imagens "ilustrativas" (MEDINA; LEANDRO, 1973) e as "photo-illustrations", segundo Souza (1997). Tais fotografias produzidas são encontradas constantemente em revistas voltadas ao público feminino/masculino, à moda, à beleza e à decoração (SOUZA, 2004).

Após observação preliminar, chegou-se à conclusão de que, na série de reportagens transmídia TAB, a composição fotográfica de

5 Exemplos publicados em 2015 pelo The New York Times:

Popes Francis' visit to America, in pictures: <http://www.nytimes.com/ interactive/2015/09/19/us/pope-francis-daily-photos.html?ref=multimedia>;

Desperate crossing: <http://www.nytimes.com/interactive/2015/09/03/ magazine/migrants.html?ref=multimedia $>$;

10 years after Katrina: $<$ http://www.nytimes.com/interactive/2015/08/26/us/tenyears-after-katrina.html?ref=multimedia $>$. 
uso mais constante é a da segunda vertente, aproximando-se da foto produzida para publicidade, algo que certamente está relacionado com os temas abordados nas edições (que muito raramente tratam de assuntos ligados ao hard news).

\section{Mapa metodológico}

Photo-illustrations ou ilustrativas, as imagens produzidas assim o são a fim de confirmar o que é descrito no texto, de persuadir o leitor sobre algo, muitas vezes sem necessariamente trazer uma nova informação. São compostas no intuito de materializar uma mise en scène desejada - pelo editor de imagens, geralmente -,corroborando o que está sendo exposto no texto e conseguindo, muitas vezes na produção de apenas uma imagem fotográfica, sintetizar grande parte do que é dito em toda a narrativa verbal.

Esse tipo de imagem encaixa-se em determinados temas de uma maneira muito mais satisfatória e persuasiva do que em quaisquer outras, uma vez que tendem a ser produzidas de maneira a levar em consideração o leitor-modelo da publicação, permitindo que este realize um exercício interno de compreensão que não existiria numa foto referencial. Ao abordar o caráter da mensagem persuasiva, Eco (2007, p. 72, destaque do autor) nos lembra que:
a mensagem estética contrapõe-se à referencial, moderadamente redundante, tendente a reduzir ao máximo toda ambiguidade e a eliminar toda tensão informativa a fim de não encorajar a contribuição pessoal do destinatário. Mas na maioria das nossas relações comunicacionais, as várias funções, dominadas pela emotiva, tendem a realizar uma mensagem persuasiva.

No objeto analisado neste artigo, a série de reportagens TAB, é possível exemplificar a capacidade de persuasão de uma imagem 
ilustrativa (ver abaixo figura 1). Nela, está projetado o leitor-modelo do TAB para esta edição em específico - provavelmente adulto, que consome produções culturais populares e fã de cinema-, além do fato de ser uma mensagem de caráter muito mais ambíguo do que referencial, no sentido de que não retrata uma situação que ocorreu sem uma produção por trás dela - e que claramente cumpre uma função emotiva, ao mesmo tempo em que desempenha uma persuasão em relação ao conteúdo verbal.

Figura 1 - Crie seu spoiler

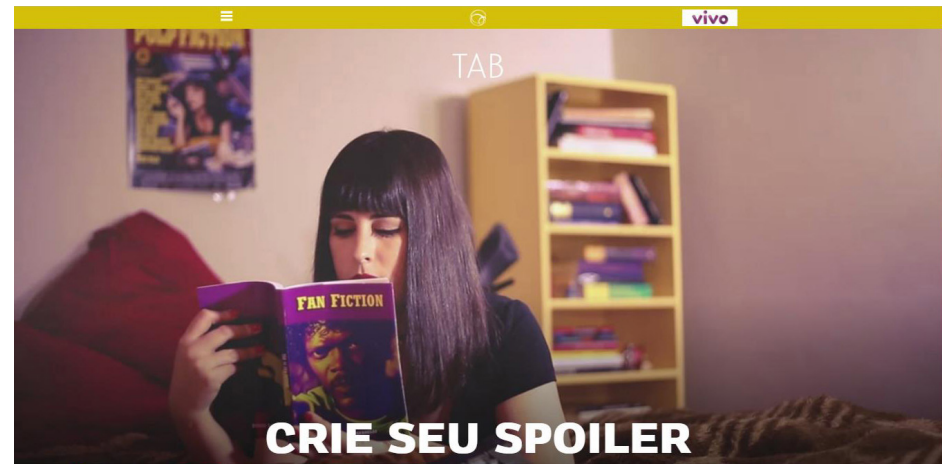

Fonte: captura de tela da reportagem Crie seu spoiler, on-line.

Provavelmente, para grande parte dos usuários que acessou a home do UOL em 21 de setembro de 2015 e se interessou, dentre outras diversas notícias e materiais, pela chamada desta edição do $\mathrm{TAB}$, a mulher deitada não representa uma jovem qualquer que lê um livro qualquer. A fotografia foi composta a fim de remeter a um filme de ficção escrito e dirigido por Quentin Tarantino em 1994. O longa, nomeado na língua original como Pulp fiction, foi ovacionado pela crítica e pelo público em seu lançamento e é, até hoje, um ícone por conta das várias cenas posteriormente reproduzidas em outros filmes.

Amulher que lê olivro intitulado Fan fiction, cuja capa é outra referência ao filme, já que reproduz a foto de um dos personagens 
principais, é uma representante do universo de leitores/escritores de fan fictions. Travestida da personagem Mia Wallace, a montagem leva a compreender que, ao mergulhar na produção/leitura de uma fan fiction, a garota literalmente está inserida na trama e pode dar novas nuances a ela - algo que é ancorado no texto verbal: "Crie seu spoiler".

A partir dessas codificações iniciais, é possível chegar a premissas que estão implícitas na imagem e, num segundo momento, mais explícitas no texto verbal, como: "hoje é possível, de dentro de seu próprio quarto, criar a sua fan fiction"; "todos podem ser criadores das tramas que amam"; "a trama não termina quando os créditos sobem ou no the end"; "aqueles que são visceralmente ligados à obra em questão são os que irão produzir ou ler fan fiction". A partir de tais premissas, é possível chegar a argumentos, como: "se você nutre uma devoção por determinada história, crie você mesmo a sua versão ou ampliação da mesma".

Premissas e argumentos eram elementos utilizados na retórica antiga, mas que, até hoje, são utilizados para a persuasão, principalmente no discurso publicitário. Eco (2007) afirma que tais artifícios retóricos podem ser utilizados não somente no texto verbal, mas também nas mensagens visuais. No caso das imagens publicitárias, estas sempre utilizarão signos de valor iconográfico, em que a conotação é um significado convencional decorrente de um aprendizado cultural, a fim de "acionar a conotação de premissas retóricas compartilhadas pela comunidade" (ECO, 2007, p. 81). O autor, que se debruça com mais afinco em análises semiológicas sobre o cinema, a pintura contemporânea, a arquitetura e a mensagem publicitária, deixa claro, entretanto, que, no caso da retórica imagética, é possível estender o escopo de investigações:

a mesma ordem de pesquisa seria possível no setor da imagem cinematográfica, do discurso televisional, da música, até chegarmos a unidades semiológicas mais vastas, hoje conhecidas como grandes blocos 
sintagmáticos e nas quais se baseia, por exemplo, a construção de enredos narrativos (ECO, 2007, p. 82).

No mapa metodológico proposto para a análise da retórica da imagem publicitária, Eco deixa claro seu posicionamento de que tal tipo de investigação deve levar em consideração imagem e texto verbal, uma vez que este último, além de ancorar a mensagem, já que a comunicação visual pode ser demasiadamente ambígua, também pode trazer diversos artifícios retóricos, algumas vezes distintos daqueles evocados pela imagem em si. Para o autor, os códigos publicitários funcionam segundo um duplo registro, o verbal e o visual.

Assume-se, neste artigo, que as imagens jornalísticas compostas para ilustração servem a objetivos semelhantes aos do discurso publicitário, com forte carga persuasiva. Assim, foram selecionadas por conveniência imagens de duas edições diferentes do TAB, publicadas entre novembro e dezembro de 2015. As edições foram escolhidas pelo fato de trazerem, ao longo da reportagem, imagens referenciais e também estéticas. Foi aplicado o mapa metodológico proposto por Eco (2007) com a finalidade de compreender como as vertentes retórica e ideológica são trabalhadas nas imagens selecionadas.

\section{Resultados}

Eco inicia o método de análise da imagem publicitária esmiuçando os níveis de codificação presentes no registro visual. O primeiro, icônico, é o nível da referencialidade. O segundo, iconográfico, é aquele em que a codificação se dá por arranjos históricos em que se utilizam elementos da "iconografia clássica que remetem a significados convencionados" (ECO, 2007, p.162) ou por iconogramas perpetuados pela própria publicidade. Aqui, deve-se levar em consideração que, na mise en scène jornalística 
voltada à ilustração, a fonte para a composição também recorre a significados que decorrem de um aprendizado cultural. O terceiro nível, o tropológico, é o das figuras de retórica clássicas aplicadas à comunicação visual.

Num momento posterior, o autor explicita mais dois níveis de codificação, agora voltados à esfera da argumentação. São eles: nível tópico, em que estão as premissas que emergem das três codificações anteriores e que evoca-se a fim de alcançar uma argumentação; e nível entimemático, que traz o entimema, conclusões das premissas então levantadas. Assim, seguindo o modelo de análise proposto por Eco (2007), a seguir são analisadas as imagens escolhidas.

\section{O presente da inovação}

Publicada em 23 de novembro de 2015, a reportagem $\mathrm{O}$ presente da inovação conta com um texto long form, com mais de duas mil palavras; uma animação de 2'58'; um vídeo de 3'57'; um infográfico animado; e um jogo do tipo quiz. O tema, futurologia, ainda não tinha sido abordado pelo TAB. O layout contém os elementos de design do TAB, incluindo a técnica de parallax scrolling. Abaixo, segue fotografia analisada.

Figura 2 - Futurologia

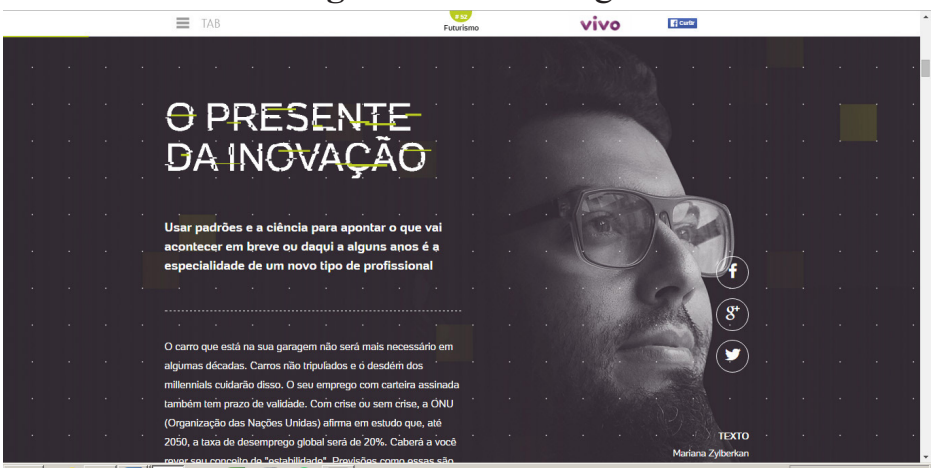


Fonte: captura de tela da reportagem Eles preveem ofuturo, on-line.

\section{Registro visual}

Imagem fotográfica em preto e branco mostra um rapaz jovem, estima-se que tenha, no máximo, 35 anos; é moreno, branco, de cabelos curtos e possui barba preta com alguns fios brancos. Usa óculos de hastes grossas. O rapaz parece olhar para algo que está acima dele. A fotografia é captada em contraplongê e tem boa resolução. É possível ver os poros na testa do rapaz. $\mathrm{O}$ fundo é escuro e há pequenos pontilhados brancos, dispostos de forma simétrica em cima da fotografia, acompanhando toda a tela. A imagem ocupa apenas o lado direito, posicionada no terceiro terço da área total da tela. O texto ocupa o lado oposto.

\section{Conotações}

O rapaz, ao olhar para cima, está em pose de possível contemplação de algo que está por vir; seu olhar não está voltado a algo que já foi, mas sim a algo que parece chegar. Presume-se, então, que seja um futurólogo. Mesmo que leve, a angulação em contraplongê corrobora a ideia de que ele possui um saber especial, conferindo-lhe um ar de superioridade, valorizando, no caso, seu conhecimento sobre o futuro.

Seu semblante é sereno; dá a entender que conhecer o futuro traz certa serenidade e sabedoria ao ser humano, como se este pudesse, de alguma maneira, controlá-lo. A imagem é aplicada, no nível tropológico, à antonomásia, pois representa todos os visionários e futurólogos que trabalham fazendo previsões sobre a sociedade no futuro.

Algumas das premissas que emergem são: "pouquíssimos sabem sobre o futuro"; "o futuro é mesmo uma incógnita”; "quem 
conhece o futuro tem algo de especial, quase sobrenatural na percepção do restante das pessoas"; "conhecer o futuro pode trazer benefícios para o presente"; "os poucos que podem prever os dias vindouros devem fazer isso em prol de evitar erros do passado"; "todos querem saber do futuro, mas é um mistério para a maioria". E, como conclusão, a ideia de que se o futuro é tão misterioso e alguns raros estudiosos podem prevê-los, vale a pena saber aquilo que eles têm a dizer.

\section{Registro verbal}

$\mathrm{O}$ texto tem como principal função de linguagem a referencial, uma vez que se trata de um texto jornalístico, mesmo com mais liberdade estilística. O objetivo é informar sobre a futurologia, seu funcionamento, seus profissionais e algumas previsões para diversos campos sociais nas próximas décadas.

No texto, não há referência a esta imagem analisada, bem como não há em relação a todas as outras. Em outras palavras, a reportagem não traz legendas de fotos que possam nomear as pessoas fotografadas, dentre outras informações. Assim, o máximo que se tem é o nome dos entrevistados grafados em cor distinta do restante do texto, o que, por proximidade, leva a crer que o nome esteja relacionado à imagem mais próxima. Entretanto, não é o que ocorre em alguns trechos (ou seja, nomes grafados em cor diferente do texto estão próximos de fotografias de outras pessoas), o que causa confusão quando se deseja compreender a quem o texto se refere.

A imagem, abaixo aproximada, é um exemplo: o fotografado é Tiago Mattos e o nome mais próximo da imagem, no texto, é o de outro futurólogo, Michell Zappa. 
Figura 3 - Exemplificação de trecho com disjunção entre imagem e nome grafado em cor de destaque

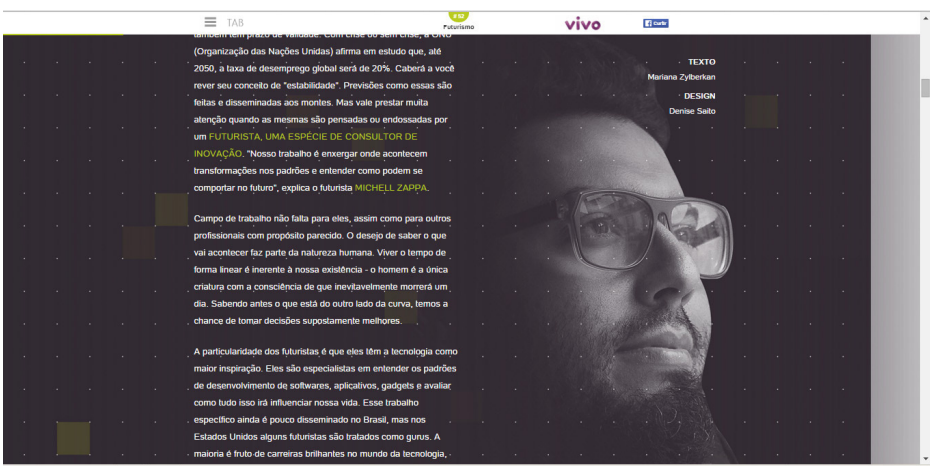

Fonte: captura de tela da reportagem Eles preveem o futuro, on-line.

Tal tipo de disjunção entre imagem e texto pode ter sido causada propositalmente, a fim de tornar as imagens mais poéticas e ilustrativas, o que é reforçado pelo tratamento de cor (em preto e branco) e pela angulação das imagens (ora em ângulo reto, ora em contraplongê). $\mathrm{Ou}$, em contrapartida, trata-se de um descuido por parte da equipe que produziu a reportagem e não se atentou para a necessidade de relacionar entrevistados e suas respectivas imagens.

Figura 4 - Exemplo de contraplongê em outra fotografia da mesma reportagem

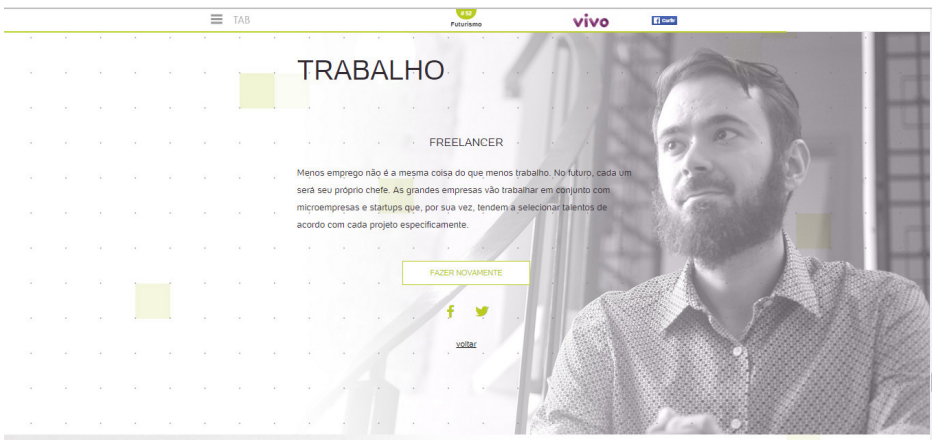


Fonte: captura de tela da reportagem Eles preveem o futuro, on-line.

Ao contrário do que ocorre na publicidade, o texto não serve para ancorar a imagem. Aqui, se faz necessária uma adaptação da metodologia de Eco (2007), uma vez que, neste caso, o texto é o elemento principal, a espinha vertebral da grande reportagem transmídia.

Assim, se na publicidade "[...] o registro verbal tem a função precípua de ancorar a mensagem, porque frequentemente a comunicação visual se mostra ambígua e conceitualizável de modos diversos" (ECO, 2007, p. 161), pode-se inferir que, especificamente nesse tipo de imagem produzida para reportagem jornalística, isso se inverte, uma vez que muita pouca informação nova é veiculada por meio da fotografia em si, já que esta é composta com o intuito de ilustrar o texto.

\section{Relações entre os dois registros}

O registro visual e o registro verbal possuem conotações semelhantes, uma vez que, no texto, também é possível compreender a ideia de que os futuristas detêm um conhecimento raríssimo e, portanto, um certo poder. A persuasão contida nas imagens e no texto é suave, sem grandes pretensões ideológicas. Trata-se de uma mensagem redundante na vertente retórica e na vertente ideológica.

Isso ocorre por conta da própria temática da reportagem, neutra, em que as previsões mais radicais se darão (ou não) num tempo futuro, assim, impassível de serem julgadas de maneira mais séria no momento presente. Eco (2007) estabelece, entretanto, possíveis combinações distintas dessa, em que se articulam diferentemente os valores da informação e da redundância tanto em relação à retórica como em relação à ideologia presentes em materiais que conjugam imagem e texto verbal. 


\section{Fim do recreio}

Publicada em 14 de dezembro de 2015, a reportagem Fim do recreio explora um tema que esteve presente na imprensa durante as semanas anteriores à sua publicação: os protestos dos estudantes e a ocupação das escolas públicas em São Paulo ocorridos após decisão do governo em reorganizar o ensino do estado. O texto da reportagem contém mais de duas mil e trezentas palavras, além de uma animação de 2'21', uma galeria de imagens em formato de quiz, um vídeo de 1'57" e um painel interativo, que reproduz postagens de usuários em redes sociais com a hashtag \#escoladossonhos. $\mathrm{O}$ layout também traz a técnica parallax scrolling. A seguir, a imagem que será analisada segundo o mapa metodológico proposto por Umberto Eco.

Figura 5 - Escola do futuro

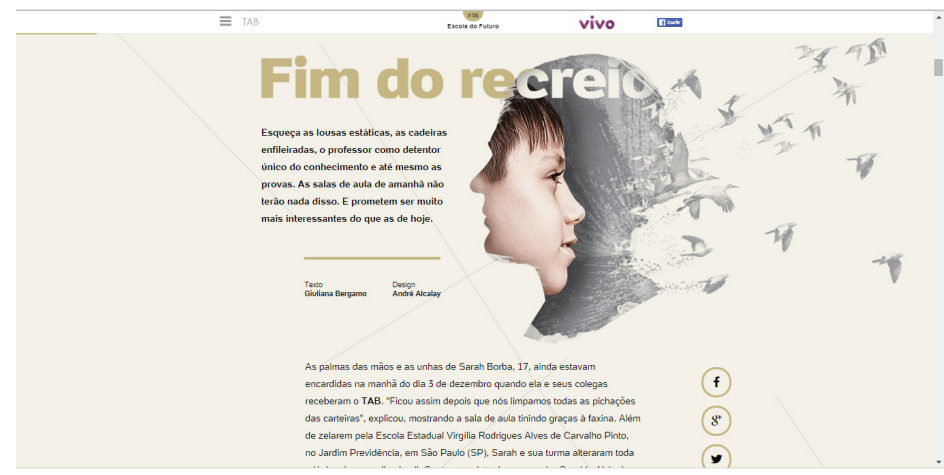

Fonte: captura de tela da reportagem A escola do futuro, on-line.

\section{Registro visual}

A fotografia mostra um garoto de perfil, olhando para o lado direito, como se estivesse visualizando algo. $\mathrm{O}$ garoto tem cabelos castanhos e curtos, é branco e aparenta ter cerca de dez anos. A 
foto está inserida dentro de uma silhueta de adulto - provavelmente homem pela silhueta do cabelo. O rosto de ambos (silhueta de adulto e imagem do garoto) está voltado a posições diferentes, sendo que enquanto a ponta do nariz do menino aponta para a direita, a extremidade do nariz da silhueta direciona-se para a esquerda. Da silhueta, que é delineada e preenchida pela cor cinza em tom mais escuro e mais claro, surgem, na parte externa da cabeça, pássaros voando para fora da página, na direção em que o garoto olha. A montagem de foto e ilustrações ocupa o terceiro e quarto terços da área total da tela. O título, em tom de ocre, se sobrepõe à imagem e, ao adentrar à área por ela ocupada, ganha o tom de cinza - o mesmo da silhueta.

\section{Conotações}

A imagem do garoto dentro da silhueta de um adulto é uma metáfora que sintetiza a ideia de que toda pessoa madura já foi criança um dia. Os pássaros cumprem uma função estética que sugere a sensação de liberdade, de avanço, de crescimento. Assim, surgem premissas diferentes, mas que contêm, de certa forma, essa ideia. Por exemplo: "é na infância que se planta o futuro", "devemos pensar na educação e formação das crianças, pois aí está o futuro", "uma criança é uma semente que pode trazer frutos bons ou ruins - conforme sua criação". Entretanto, essas não são as únicas premissas possíveis, uma vez que, quando observada em conjunto com o texto, a interpretação da imagem pode abranger mais significados, como será observado a seguir.

\section{Registro verbal}

A silhueta do adulto pode também representar a figura do professor. Aqui, a necessidade da ancoragem textual é significativa 
para esse entendimento da imagem, como propunha Eco (2007). No texto da reportagem, é mostrada a realidade de alguns colégios e filosofias de ensino que consideram a construção do conhecimento como uma via bilateral de troca de aprendizados entre aluno e professor. Neste caso, surgem premissas como "a escola do futuro é feita entre professor e aluno", "o aluno não é apenas um copo vazio a ser preenchido", "a formação de conhecimento só existe com participação", "o professor deve levar em consideração a realidade do aluno", "o professor precisa interiorizar o seu aluno para ensinar de maneira efetiva", "o aluno precisa se sentir parte do aprendizado e da escola".

A função de linguagem do texto predominante é a referencial, mas há espaços para trechos e títulos mais criativos e lúdicos.

\section{Relações entre os dois registros}

Texto e imagem corroboram, por meio de artifícios retóricos, a mesma ideologia: a de que a escola precisa mudar e o caminho está em colocar o aluno como participante ativo do conhecimento. Há também uma redundância retórica tanto na imagem como no texto. Apesar de ser um pouco mais sofisticada, a persuasão da imagem analisada serve para reforçar o que está sendo dito no texto.

\section{Considerações finais}

O presente artigo teve como finalidade verificar a possibilidade de aplicação da metodologia proposta por Umberto Eco em $A$ estrutura ausente não apenas à análise de peças publicitárias, mas também à investigação sobre imagens produzidas para ilustração no jornalismo, com foco na grande reportagem transmídia. A fim de lançar luz a aspectos que definem a identidade visual do TAB, foram investigadas articulações retóricas e 
informativas que são utilizadas em imagens do veículo em questão.

Nesta análise, concluiu-se que, para essa vertente de imagens produzidas no jornalismo, é possível amplificar a metodologia de Eco, a fim de desconstruir elementos que, juntos, levam à criação de significado baseada em premissas iconográficas e na retórica. Além disso, evidenciou-se que, nas imagens analisadas, a redundância retórica é muito mais marcante do que a redundância informativa, uma vez que as imagens foram construídas ou manipuladas a fim de corroborar o que está escrito no texto.

Vale lembrar que, apesar da possibilidade de ampliação da metodologia de Eco para um escopo de produções jornalísticas, há diferenças marcantes em relação ao material publicitário. Em primeiro lugar, na propaganda, o texto tem a função de ancorar a imagem enquanto que, no jornalismo, isso pode ou não ocorrer. A imagem no jornalismo, mesmo ilustrativa, pode ser tão referencial que não necessitaria de texto para explicá-la, trazendo, por si só, uma grande carga informativa, sem espaço para ambiguidades. Já em outros casos, principalmente em produções que envolvem manipulações imagéticas (montagens, efeitos), a imagem pode necessitar do texto para que seja adequadamente compreendida.

Em relação aos registros, o visual da imagem jornalística pode vir a ser muito mais simples do que o da imagem publicitária, que se serve de artifícios estéticos a fim de despertar o impulso pelo consumo. Por outro lado, o registro verbal do texto jornalístico tenderá sempre a ser de maior tamanho e complexidade em relação ao texto publicitário, já que a intenção daquele é informar, narrar acontecimentos, contextualizar uma situação. Assim, enquanto a função da mensagem publicitária pode variar entre emotiva, fática, metalinguística, estética, imperativa, além da referencial, no jornalismo, preponderantemente, a função mais utilizada será esta última.

Não à toa, a imagem ilustrativa é utilizada para corroborar o texto, no jornalismo. Essa manipulação sofisticada foi ganhando espaço no jornalismo aos poucos e tem longa tradição 
em determinados segmentos, como as revistas direcionadas a um público específico. É possível inferir que, hoje, há uma hibridização de linguagens que buscam informar e persuadir. Se as imagens ilustrativas no jornalismo contêm elementos retóricos da publicidade, sendo, inclusive, passíveis de análise via metodologia originalmente proposta por Eco para a investigação de propagandas, a publicidade, por sua vez, tem utilizado o valor da referencialidade da informação jornalística para vender seus produtos, encarnados em publieditoriais.

Essas hibridizações têm a imagem como protagonista, pois por meio dela é possível corroborar, informar, persuadir. Sua força não diminui no cenário atual, de convergência midiática e cultural. Aqueles que sabem como utilizá-la o fazem para qualquer plataforma e finalidade, como nos lembra Freund (1995, p. 201): “dirigindo-se à sensibilidade, a fotografia é dotada de uma força de persuasão que aqueles que dela se servem como meio de manipulação exploram conscientemente".

Por fim, deve-se salientar que o artigo, de caráter experimental e exploratório, não é em hipótese alguma definitivo, necessitando, assim, de contribuições posteriores que avancem na questão inicialmente aqui abordada.

\section{Referências}

A ESCOLA do futuro. UOL, São Paulo, n. 55. Disponível em $<$ http://tab.uol.com.br/escola-do-futuro $>$. Acesso: 31 dez. 2016.

ANDERSON, Chris; BELL, Emily; SHIRKY, Clay. Jornalismo pós-industrial: adaptação aos novos tempos. Revista de Jornalismo ESPM: edição brasileira da Columbia Journalism Review, São Paulo, p. 30-39, abr./jun. 2013.

ANDERSON, Scott; PELLEGRIN, Paolo. Desperate crossing. 
The New York Times, 3 set. 2015. Disponível em: <http://www. nytimes.com/interactive/2015/09/03/magazine/migrants.html $>$. Acesso em: 19 dez. 2015.

CANAVILHAS, João. Jornalismo Transmídia: um desafio ao velho ecossistema midiático. In: RENÓ et al. (Org.). Periodismo Transmedia: miradas múltiples, Barcelona: UOC, 2014.

CASADEI, Eliza Bachega. Experiências fotojornalísticas em um cenário de convergência midiática: os novos espaços de autoria. In: BRONOSKY, M. E.; CARVALHO, J. M. (Orgs.). Jornalismo e convergência. São Paulo: Cultura Acadêmica, 2014.

ECO, Umberto. A estrutura ausente: introdução à pesquisa semiológica. 7. ed. São Paulo: Perspectiva, 2007.

ELES preveem o futuro. UOL, São Paulo, n. 52. Disponível em $<$ http://tab.uol.com.br/futurismo/>. Acesso: $31 \mathrm{dez} .2016$.

FREUND, Gisèle. Fotografia e sociedade. 2. ed. Lisboa: Vega, 1995.

JENKINS, Henry. Cultura da convergência. São Paulo: Aleph, 2008.

LONGHI, Raquel Ritter. O turning point da grande reportagem multimídia. Famecos, Porto Alegre, v. 21, n. 3, p. 897-917, set./ dez. 2014.

MEDINA, Cremilda; LEANDRO, Paulo Roberto. A arte de tecer o presente: jornalismo interpretativo. São Paulo: Média, 1973.

PERSICHETTI, Simonetta. A encruzilhada do fotojornalismo. Discursos fotográficos, Londrina, v. 2, n. 2, p. 179-190, 2006. 
POPE Francis' visit to America, in pictures. The New York Times, set. 2015. Disponível em: <http://www.nytimes.com/ interactive/2015/09/19/us/pope-francis-daily-photos.html?_r=0>. Acesso em: 19 dez. 2015.

RENÓ, Denis Porto. Transmedia journalism and the new media ecology: possible languages. In: RENÓ, Denis et al. (Orgs.). Periodismo transmedia: miradas múltiples, Barcelona: UOC, 2014.

RIGHETTI, Simone; CARVALHO, Ruy Quadros de. Crise do jornalismo impresso e perspectivas para o futuro: um estudo dos dois maiores jornais diários impressos do Brasil. In: CONGRESSO BRASILEIRO DE CIÊNCIAS DA COMUNICAÇÃO INTERCOM, 31., 2008, Rio Grande do Norte. Anais eletrônicos... São Paulo: Intercom, 2008. Disponível em: <http://www.intercom. org.br/papers/nacionais/2008/resumos/R3-2032-1.pdf $>$. Acesso em: 23 maio 16.

ROBERTSON, Campbell; FAUSSET, Richard. 10 YEARS after Katrina. The New York Times, aug. 2015. Disponível em: <http:// www.nytimes.com/interactive/ 2015/08/26/us/ten-years-afterkatrina.html>. Acesso em: 19 dez. 2015.

SALAVERRÍA, Ramon. Multimedialidade: informar para cinco sentidos. In: CANAVILHAS, João (Org.). Webjornalismo: 7 caraterísticas que marcam a diferença. Covilhã: Labcom, 2014.

SOUZA, Jorge Pedro. Fotojornalismo performativo: o serviço de fotonotícia da Agência Lusa de Informação. 1997. Tese de Doutorado originalmente apresentada em Santiago de Compostela: Universidade de Santiago de Compostela. Disponível em: <http:// bocc.ubi.pt/pag/sousa-jorge-pedro-fotojornalismo-tese.html>. Acesso em: 20 dez. 2015. 
- Fotojornalismo: introdução à história, às técnicas e à linguagem da fotografia na imprensa. Florianópolis: Letras Contemporâneas, 2004.

TODO mundo mente. UOL, São Paulo, n. 4. Disponível em $<$ http:// tab.uol.com.br/mentira>. Acesso em: 23 maio 2016.

UOL lança o TAB, novo projeto editorial interativo. UOL, São Paulo, 13 out. 2014. Disponível em: <http://noticias.uol.com. br/ultimas-noticias/redacao/2014/10/13/uol-lanca-o-tab-novoprojeto-editorial-interativo.htm>. Acesso em: 11 fev. 2015. 